\title{
Anadolu Üniversitesi Örgün Öğrencilerinin Üniversitelerine Bağlılıklarının Öğrenci Memnuniyet Modeli ile İncelenmesi*
}

\author{
Examination of the Loyalty of Formal Students of Anadolu University via \\ Student Satisfaction Model
}

\author{
Doç.Dr. Köksal Büyük - Yrd.Doç.Dr. Murat Akyıldız
}

\section{Öz}

Yükseköğretim kurumlarının performanslarının öğrencilerinin gözünden değerlendirilmesi son yıllarda giderek önem kazanmaktadır. Yükseköğretim kurumlar, öğrencilerinin memnuniyet düzeylerini arttırarak kurumun tercih edilirliğini arttırmak ve küresel eğitim pazarından daha çok pay almak istemektedir. Öğrencilerin gözünden incelendiğinde yüksek ve düşük memnuniyet duyulan boyutlarm belirlenmesi sayesinde yükseköğretim kurumunun sahip olduğu kaynakların memnuniyeti daha çok arttıracak boyutlara aktarılması imkânı kazanılabilir. Bu çalışmada Anadolu Üniversitesi örgün öğrencilerinin üniversiteye bağlllkkları üniversiteye bağlllık modeli bağlamında incelenmiştir. Üniversiteye bağlllık modeli üniversitenin fiziksel imkânlarına, akademik, sportif ve kültürel faaliyetlerine, ögrencilerin bireysel akademik gelişim süreçlerine, üniversitenin zihinsel imajına ve üniversiteye bağhllı̆̆a ilişkin algıları içermektedir. Araştırmada test edilen model öğrencilerin üniversitenin fiziksel imkânlarma, faaliyetlerine ve akademik gelişim imkânlarına yönelik algılarının üniversite imajın etkilediğini, bu faktörlerden etkilenen üniversite imajının ise üniversiteye olan bağlliğ̆ etkilediğini varsaymaktadır. Geliştirilen üniversiteye yönelik görüşler ölçeğinin güvenirlik ve geçerliliğini belirleyebilmek amacıyla doğrulayıcı faktör analizi uygulanmışve tüm boyutların ortalama çıkarılan varyans (AVE) ve birleşik güvenirlikleri (Composite Reliability) hesaplanmıştır. Ölçeğin yüksek derecede geçerli [Chi square $\left(c^{2}=5268.50, d f=1444, p<0.001\right)$, Chi square/ $d f\left(c^{2} / d f=3.65\right)$, RMSEA (0.034), NFI (0.97), NNFI (0.98), CFI (0.98), IFI (0.98)] ve güvenilir (boyutların birleşik güvenirlik değerleri 0,77-0,96 arasındadır) olduğu görülmüsstür. Ölçeğin uygulanmasindan elde edilen veriler ile üniversiteye bağlılık model arasındaki uyumun yüksek olduğu görülmüştür Chi square $\left(c^{2}=\right.$ 137.82, $d f=52, p<0.001)$, Chi square/df $\left(c^{2} / d f=2.65\right)$, RMSEA (0.027), NFI (0.99), NNFI (0.99), CFI (1.00), IFI (1.00). Modeli iyiliği katsayıları için elde edilen değerler modelin toplanan verilerle çok iyi uyum sağladığını göstermektedir. Test edilen model öğrencilerin üniversiteye olan bağhllklarını iyi derecede açıklayabilen bir modeldir.

Anahtar Kelimeler: Öğrenci Memnuniyeti, Bağlllık, İmaj

\begin{abstract}
Evaluation of the performances of universities in the eyes of their students tend to get more important in recent years. Universities want to increase the preferability of the institutions and participate the global education market more by increasing the satisfaction of their students. Determining the dimensions which are
\end{abstract}

Doç.Dr. Köksal Büyük, Anadolu Üniversitesi AÖF, koksalbuyuk@anadolu.edu.tr

Yrd.Doç.Dr. Murat Akyıldız, Anadolu Üniversitesi AÖF, muratakyildiz@anadolu.edu.tr

* Bu Çalışma Anadolu Üniversitesi Bilimsel Araştırma Projeleri Komisyonu tarafından kabul edilen 1409E393 nolu proje kapsamında desteklenmiştir. 
of low or high satisfaction enables the distributions or sources more accurately in order to increase satisfaction. In this study, loyalty of formal students of Anadolu University is examined by the university loyalty model. The university loyalty model consists of the perceptions of physical facilities, academical, sportive and cultural activities, loyalty to the university and the image of university. The model tested in the study assumes that the image of the university is affected by students' perception of the pyhsical facilities, activities and chances of academical improvement and the loyalty to university is affected by the image of the university that is shaped by these perceptions. Confirmatory factor analysis is applied in order to determine the validity and the average variance extracted values of all dimensions (AVE) and composite reliabilities are calculated to determine reliability of the Opinions Towards University scale. After analyses the validity [Chi square $\left(c^{2}=5268.50, d f=1444, p<0.001\right)$, Chi square/df $\left(c^{2} /\right.$ $d f=3.65)$, RMSEA (0.034), NFI (0.97), NNFI (0.98), CFI (0.98), IFI (0.98)] and reliability (composite reliability values change between 0.77 and 0.96$)$ of scale have found high enough. Goodness of fit of data and model is found high [Chi square $\left(c^{2}=137.82, d f=52\right.$, $p<0.001)$, Chi square/df ( $\left.c^{2} / d f=2.65\right)$, RMSEA (0.027), NFI (0.99), NNFI (0.99), CFI (1.00), IFI (1.00)]. Godness of fit values of model have shown that model fits the data well. The model explains the loyalty of students to university well.

Keywords: Student Satisfaction, Loyalty, Image

\section{Giriş}

Rekabet günümüzde sadece ticari alanda değil eğitim alanında da önem kazanan bir kavramdır. Bu nedenle üniversitelerin küresel düzeyde bir rekabet içerisinde olması performanslarını geliştirme baskısını da beraberinde getirmektedir. Üniversiteler, amaçlarını, yapılarını, süreçlerini ve çıtılarını yeniden gözden geçirerek rekabet avantajı sağlayacak biçimde açılımlar yapmak istemektedirler. Küresel eğitim pazarı her geçen gün büyümekte ve üniversiteler bu pazardan daha fazla payı almak için kalite çalışmalarına önem vererek sürdürülebilir bir rekabet avantajı yakalamayı istemektedirler (Popli, 2005, s.17-18).
Kamu örgütlerinin geçmişine bakıldığında özel sektör ile birbirlerini yakından izlemeleri ve karşılıklı etkileşim içinde bulunmaları gerekirken bu iki alanın farklı biçimde gelişim gösterdiğini gözlemleyebiliriz. Bu iki sektörün buluşması yeni kamu işletmeciliği yaklaşımı ile 1980'li yılların başlarına dayanmaktadır. Özel sektör kaynaklı performans yönetimi, yeni kamu yönetimi anlayışı çerçevesinde kamu örgütleri içinde gerekli bir yönetim aracı haline dönüşmüștür. Birçok kamu kuruluşu gibi üniversiteler de kaynak tahsisini ve önceliğini daha iyi yapmak, ürettikleri hizmetlerin kalitelerini arttırmak, örgütsel planlamayı daha sağlıklı yapmak, harcamalarında verimlilik ve tutumluluk sağlamak amacıyla etkin bir performans yönetim sistemi kurmayı arzulamaktadırlar.Yükseköğretim kurumlarının en önemli hedeflerinden biri öğrenci memnuniyetinin sağlanması, istek ve gereksinimlerinin karşılanmasıdır.

\section{Yükseköğretimde Öğrenci Memnuniye- tinin Bağlılığa Etkileri}

Yükseköğretimden memnuniyete dair çalıșmalarda eğitimin kalitesine yönelik pek çok kriteri göz önünde bulundurmak gerekir. Sadece öğrencilerin hizmetten duydukları memnuniyete bağlı olarak ifade ettikleri hizmet kalitesi değerlendirmeleri tek başına yeterli olmamakla birlikte günümüzde en çok bu boyutun kullanıldığı da bir gerçektir. Eğitim hizmetlerini ölçmeye çalışken sadece sınıf içi akademik faaliyetleri esas almak doğru bir yaklaşım olmayacaktır. Öğrenen-Öğretici ilişkisi, akademik danışmanlık ilişkisi, eğitim programı gibi unsurlar da dikkate alınmalıdır (Dolmans vd., 2003, s.212). Öğrencilerin memnuniyetlerinin, okullarına olan bağlılıklarını artıracağı iddia edilebilir. Bu sebeple bu araştırmada, üç önemli memnuniyet unsuru üzerinde durulacaktır. Bunlar akademik memnuniyet, fiziksel memnuniyet ve faaliyetlerden kaynaklanan memnuniyettir.

\section{Akademik Memnuniyet}

Akademik memnuniyet kendi içerisinde üç alt başlık altında değerlendirilecektir. Söz konusu alt başlıklar “akademik danışmanlık ve rehberlik", "öğretme süreci” ve "akademik gelişim algısı” şeklindedir. 
Öğrenci ve Öğretici arasındaki sınıf içi ve dışı ilişkiler öğrencinin memnuniyeti üzerinde önemli bir etkiye sahiptir (Kuh ve Hu, 2001, s.311). Özellikle de akademik danışmanlık ve rehberlik, öğrencilerin okullarına olan bağlılıklarını doğrudan etkileyebilmektedir. Akademik danışmanlık hizmetleri, öğrencilerin hayat ve kariyer amaçlarını belirleyen ya da bu amaçları keşfetmelerinde onlara yardımcı olan bir süreç olarak algılanmaktadır (King, 1993, s.51). Zira akademik danışmanlık ve rehberlik hizmeti sunulduğunda öğrencilerin okulun faaliyetlerine katılımı artış gösterirken motivasyonları da yükselecektir. Bu aşamada öğrenciler bilgili birilerini bulabilmek, bilmedikleri noktaları öğrenebilmek ve düşüncelerini paylaşabilmek isteyeceklerdir (Phan ve diğerleri, 2015, s.38). Bu yüzden okulun programı ve öğrenci sorunları hakkında bilgilendirme hizmeti sunmak birçok sorunun ortadan kalkmasını sağlayacaktır. Akademik danışmanlık ve rehberlik hizmeti hem okul hakkındaki belirsizliklerin anlaşılır hale gelmesini sağlamakta hem de öğrencilerin bakış açılarını ve sorunlarını olumlu yönde etkilemektedir (Brooks, 2012, s.3). Öğretim elemanları ile sınıf dışında kurulan iletişimin öğrencileri kariyerlerini konusunda düşünmeye sevk etti$\breve{g} i$, eğitim deneyimlerine dair memnuniyeti artırdığı, entelektüel olarak katkılar sağladığı tespit edilmiştir (Clark vd., 2002, s.831).

Günümüzde öğrencilerin bir yükseköğretim kurumu hakkında bilmek isteyecekleri birçok şey bulunmaktadır. Farklı konular hakkında bilgi sahibi olmayan öğrencinin kendisini okuluna ait hissetmesi ve kat1$\operatorname{lım}$ göstermesi zorlaşacaktır. Healey ve arkadaşları (2014)'e göre kurumsal yapı, kurumun sistemleri, stratejiler, prosedürler, politikalar, maddi konular, akademik konular, sergilenmesi gereken davranışlar, eğitmenler ve benzeri çeşitli konular öğrenciler tarafından bilinmelidir (Healey ve diğerleri, 2014, s.17).Bu konular hakkında bilgi sahibi olunmadığ zaman öğrenci kendisini kurumun bir parçası olarak görmekte zorlanacaktır. Bu sorunun ortadan kald1rılması için ise iyi bir etkileşimin ortaya çıkarılması gerekmektedir. Eğitmenlerin, rehberlik faaliyeti gösteren bireylerin ve öğrencilerin birbirlerinden uzak olmaları öğrencilerin bağlılı̆̆ını azaltır. Bu sorunun ortadan kaldırılması için ise kesinlikle söz konusu taraflar arasında iyi bir etkileşim sistemi oluşturulmal1dır (Kuo vd., 2013, s.18). Bu sayede öğrenciler yeterli akademik danışmanlık ve rehberlik hizmeti almış olacaktırlar. Kaliteli danışmanlık hizmeti sadece öğrencilerin ders seçimlerinde değil, yönlenebilecekleri yeni durumlardan da haberdar olmalarını sağlaması açısından akademik süreçte önemli bir rol oynamaktadırlar (King, 1993, s.8).

Akademik danışmanlık ve rehberlik hizmetinin sunulması ve bu yolla öğrencilerin katılımının, motivasyonunun ve bağllllğının yükseltilmesi için eğitmenlerin ve akademik danışmanlık-rehberlik hizmeti sunan görevlilerin ulaşılabilir olmaları önemlidir. $\mathrm{Bu}$ bireylerin öğrenciler ile yakın ilişki içerisinde olmaları ve ihtiyaç duyduklarında öğrencileri yeterli bir biçimde bilgilendirmeleri şarttır. Bu aşamada yüz-yüze görüşme, telefon yada mail gibi çeşitli kaynakların kullanılması faydalı olacaktır. Önemli olan hangi çevrede iletişime geçildiği değil, iletişim sürecinin öğrencinin ihtiyacını ne ölçüde karşıladığıdır (Dixson, 2010, s.2-3). Aynı zamanda iyi bir akademik danışmanlık hizmeti, öğrencinin akademik performansını ve üniversitedeki deneyimine ilişkin memnuniyetini arttırmaya yönelik olumlu ve önemli bir etkiye sahiptir (King, 1993, s.66).

Akademik memnuniyetle doğrudan ilgili ikinci konu öğretme sürecidir. Öğretme süreci öğrencilerin ihtiyaçlarını karşıladığında, öğrenciler tarafından okula karşı olumlu bir tutum geliştirilmesi kaçınılmaz olacaktır. Bu noktada çok sayıda yöntem kullanılabilir. Öncelikle öğretme sürecinin zenginleștirilmesi önemlidir. Hem yüz-yüze eğitimin, hem de uzaktan eğitimin başarılı bir şekilde sunulması, öğretme sürecindeki olumlu aktivitelere bir örnek olarak sunulabilir (Delialioğlu, 2012, s.311). Benzer şekilde, karma öğrenme de öğrencilerin performanslarında bir yükselişin görülmesini sağlamaktadır. Söz konusu performans artışı ile beraber farklı öğrenme deneyimleri kazanılmakta ve tatmin düzeylerinde bir artış görülmektedir (Henrie vd., 2015, s.132).Tüm bu gelişmelerin okula karşı olan bağlılığı arttırdığ 1 ileri sürülebilir. Barak ve diğerleri (2016)'ne göre öğrenme sürecinin motivasyonu yükselteceği unutulmamalıdır. Öğrenme ortamının ve öğretme sürecinin doğru bir biçimde oluşturulması hem akademik performansın yükselmesi ile sonuçlanmakta, hem de öğrencilerin tatmin düzeylerinin artmasını sağlamaktadır. Yazarlara göre daha özgür, yeterince zor, diğer öğrencilerle etkileşim içerisinde olan ve benzeri özellikleri taşıyan öğretme süreçlerinde öğrenciler dersi çok daha fazla benimseyecektirler (Barak vd., 2016, s.50). 
Öğretme sürecinin öğrencilerin kuruma olan bağl1lığını artırmak için kullanılması aşamasında öğrencilerin katılımı da gözden kaçırılmaması gereken bir unsurdur. Öğrencilerin öğretme süresince ne derecede aktif oldukları önemlidir. Fiziksel ve zihinsel olarak sürecin içinde olan öğrencilerin tatmin düzeyleri yükselmekte ve kendilerini kurumun bir parças1 olarak görmeleri kolaylaşmaktadır (Joo vd., 2011, s.1662). Kendilerini okulun bir parçası olarak gören öğrencilerin öğretme sürecinde aktif rol alarak s1nıf içerisinde ve sınıf dişarısında yapılan aktivitelere daha çok katılmaktadırlar. Bu öğrenciler farklı takımlarda da kendilerine yer bulabilmekte ve süreçle iç içe olmaktadırlar (Ku vd., 2013, s.923).

Öğrencilerin üzerinde önemli durdukları bir diğer husus akademik gelişim konusudur. Akademik gelişim algısı, öğrencilerin nihai hedeflerinden biri olmas1 nedeniyle önemlidir. Bir öğrencinin herhangi bir üniversitede bulunmasının temel nedenleri arasında akademik olarak iyi yerlere gelme isteği bulunmaktadır. Öğrencinin, bünyesinde bulunduğu üniversitenin onu iyi yerlere getireceğine inanması üniversiteye olan bağlılığını yükseltecektir. Dahası bu durum, öğrencinin hem öğretme sürecine aktif bir biçimde katılmasını hem de devamsızlıktan uzak kalmasını sağlayacaktır (Kahu vd., 2013, s.792).Öğrenci memnuniyetine yönelik araştırmalar göstermektedir ki öğrenme, çok güçlü bir biçimde dersten sağlanan doyumla gerçekleşmektedir (Guolla, 1999, s.87).

Öğrencilerin akademik faaliyetlere karşı olan tutumları göz önünde bulundurulurken üç nokta göz önünde bulundurulmalıdır. Bunlar öğrencinin içeriği ne derecede bilgilendirici buldukları, içeriği ne derecede faydalı buldukları ve materyaller hakkında ne düşündükleridir (Liaw, 2008, s.871). Akademik olarak iyi yerlere geleceği düşüncesi öğrencinin tatmin düzeyini kaçınılmaz olarak artıracaktır. Bu aşamada öğrenci, hem üniversitenin kendisini iyi yerlere getireceğini hissetmeli, hem de gerçekleştirilen tüm aktivitelerin faydalı olacağını düşünmelidir. Üniversite tarafından gerçekleştirilen akademik faaliyetler öğrenci tarafından akademik hedeflere ulaşılmasını sağlayan araçlar olarak görüldüğünde motivasyon ve bağlllık seviyesi doğal olarak yükselecektir (Joo vd., 2011, s.1654). Ayrıca öğrenci, kendi eğitim sürecinde bazı değişiklikleri yapabilme imkânına sahip olduğunda bağlllık adına olumlu gelişmeler gözlemlenebilir. Öğrenci, kendi geleceğine yönelik akademik tercihlerde istekleri doğrultusunda tercihler yapabildiğinde akademik amaçlarına ulaşabileceğine olan inancı yükselecektir (Kou vd., 2014, s.37). Öğrencilerin eğitim sürecinde aktif olarak rol almaları, eğitim programlarına olan ilgilerini artırır (Trowler, 2010, s.25).

Akademik faaliyetlere karşı olan memnuniyetten bahsederken üzerinde durulması gereken son nokta öğrenmeler arasındaki ilişkidir. Diğer bir ifadeyle, yeni öğrenmeler ve eski öğrenmeler arasındaki ilişki memnuniyeti etkileyecektir (Phan vd., 2015, s.36). Öğrenciler eski öğrenmelerini yeni öğrenme süreçlerinde kullanabildiklerinde daha iyi sonuçlar alınabilir (Shen vd., 2013, s.11).

\section{Fiziksel Memnuniyet}

Fiziksel memnuniyet iki algı üzerinde durmaktadır. Bunlar güvenlik algısı ve fiziksel yeterlilik algısıdır. Bireyin kendisini eğitim kurumunun bir parçası olarak görmesi ve bağlllığının artması için kendisini güvende hissetmesi gerekmektedir. Öğrenme ortamlarının ve fiziksel çevrenin güvenli olması, öğrencinin kendisini daha rahat hissetmesini sağlayacaktır (Gibbs ve Poskitt, 2010, s.15). Güvenlik sadece okul içerisinde değil hayatın her alanında gereklidir. İhtiyaçlar hiyerarşisine göre güvenlik hayatın en önemli ihtiyaçlarından biridir (Maslow, 1943). Bu sebeple okul ortamının fiziksel, zihinsel ve psikolojik olarak güvenli olması bir zorunluluktur (NCPC, 2013).

Okul ortamında güvenliğe zarar verebilecek çok çeşitli unsurlar olabilir. Doğal tehditler, teknolojik tehditler ve insan kaynaklı tehditler öğrencilerin okula olan bağlılıklarını olumsuz yönde etkileyen unsurlar arasındadır. Okul içerisinde ortaya çıkması muhtemel çok çeşitli tehdit unsurları vardır. Söz konusu tehdit unsurlarının bazıları şu şekilde listelenebilir(Massachusetts Task Force Report, 2014, s.3):

- Silah,

- Kavga,

- Terörizm,

- Kaza,

- Yangin,

- Sağlık sorunları 
Yukarıda sayılan ve benzeri unsurlar öğrencilerin okula karşı olumsuz tutumlar geliştirmeleri ile sonuçlanacaktır. Öğrenciler ise daha çok adaletli, karşılıklı saygının olduğu, okul yöneticilerinin desteklerinin görüldüğü katılımcı bir çevre isteyecektirler (Gibbs ve Poskitt, 2010, s.11).

Güvenliğe ek olarak, öğrenciler fiziksel imkânların yeterli olmasına da büyük önem vermektedirler. Fiziksel açıdan yetersiz olan ortam öğrencilerin tatmin duygularını azaltacak ve okulun yetersiz olduğu düşüncesine girmeleri ile sonuçlanacaktır. Okulun fiziksel imkânları ve söz konusu imkânların boyutları olumlu tutumlar geliştirmek için gereklidir. Zira fiziksel imkânların yetersizliği hem müfredatın istenilen şekilde fayda sağlamasını etkileyecek, hem de öğrencilerle beraber öğretmenlerin de verimlerini azaltacaktır (Kayakütük vd., 2012, s.184).

Okulun imkânları kadar sınıfın fiziksel durumu da okula olan bağlılığı etkileyecektir. Sınıfın fiziksel imkânlarının yeterli olması sunulan eğitimin kaliteli olmasını sağlayacaktır. Sunulan eğitimin kaliteli ve etkili olması öğrenci tatminini yükseltir. Yeterli boşluğun bulunması, malzemeleri, sıcaklık, pencereler gibi unsurların hepsi öğrencilerin tutumlarını ve verilen eğitimin kalitesini etkilemektedir (Brooks, 2012, s.2). Ayrıca fiziksel çevre temiz ve güvenli olmalıdır (Brooks, 2012, s.12).

\section{Faaliyetlerden Memnuniyet}

Öğrencilerin okula olan bağlılıklarını etkileyen son unsur faaliyetlerden kaynaklı memnuniyettir. $\mathrm{Bu}$ noktada üç alt başlık öne çıkmaktadır. Akademik faaliyetlerden kaynaklı memnuniyet, sportif faaliyetler ve kültürel faaliyetlerin öğrencilerin okula karşı olan tutumlarını etkiledikleri ileri sürülebilir.

Daha önce de belirtildiği üzere öğrencilerin üniversitede bulunmalarının temel nedenlerinden biri iyi bir akademik eğitim almaktır. Bu sebeple akademik faaliyetlerden ne derecede memnun oldukları öğrencilerin okula olan bağlılıklarını etkiler. Akademik faaliyetlere karşı öğrencilerin tutumları aynı zamanda faaliyetlere katılımlarını da etkilemektedir (Draus vd., 2014, s.242). Katılımın azalması doğal olarak öğrencilerin tatmin düzeylerinin azalması ile sonuçlanacaktır. Delialioğlu (2012)'ye göre öğrencilerin akademik aktivitelere katılımlarının az olması tatmin düzeyinin azalması, olumsuz deneyimlerin yaşanması ve okuldan uzaklaşma ile sonuçlanmaktadır (Delialioğlu, 2012, s.310). Diğer tarafta, akademik faaliyetler öğrenci tarafından çekici görülmesi ve bu süreç içerisinde doğru materyallerin kullanılması olumlu gelişmelerin yaşanmasını kolaylaştıracaktır (Joo vd., 2011, s.1655). Doğru materyallerin kullanılmasının yanında etkileşim de akademik faaliyetleri daha çekici yapacaktır. Hem öğretmen ve öğrenciler arasındaki iletişim, hem de öğrencilerin kendi aralarındaki etkileşim akademik faaliyetlere duyulan memnuniyeti artıracaktır (Joo vd., 2014, s.191).

Belirtilmesi gereken son nokta sportif ve kültürel faaliyetlerdir. Öğrenciler sadece akademik noktalara önem vermemektedirler. Öğrencilerin katılımlarını artırmak, motivasyon düzeylerini yükseltmek ve sonuç olarak bağlılıklarını olumlu yönde geliştirmek için sportif ve kültürel faaliyet imkanlarının sunulması gerekmektedir. Bu faaliyetlere katılım oranlar1nın yüksek olması doğal bir sonuçtur. Öğrencilerin bu tür faaliyetlere olan katılımları okula karşı olan tutumlarını istendik yönde değiştirecektir (Willms, 2000, s.18). Zira bu tür faaliyetler öğrencilerin olumlu davranışlar geliştirmelerine ve akademik başarılarina destek olmaktadır (NEALS, 2009, s.3). Sportif ev kültürel faaliyetler öğrencinin kendisini okulun bir parçası olarak görmesine yardım etmektedir (Willms, 2000, s.8). Aktiviteler öğrencilerin başarı duygusu yaşamalarını sağlar ve evrensel değerler kazanmaları ile sonuçlanabilir. Özgüven, sosyal açıdan gelişim ve benzeri kazanımlar sportif ev kültürel faaliyetler ile elde edilmektedir (Johnstone, 2008, s.3).

Yukarıda ayrıntıları verilen akademik, fiziksel ve sosyokültürel faaliyetlerden duyulan memnuniyet derecesinin öğrencilerin eğitim görmekte oldukları kuruma ilişkin algılarını ve bağlılıklarını etkilemesi beklendik bir durumdur. Öğrencilerin eğitim gördükleri eğitim kurumuna ilişkin bir imaja sahip olmaları, bu imajın olumlu bir içeriğe sahip olması öğrencilerin eğitim gördükleri kuruma olan bağlılıklarını arttıracaktır. Kurumsal bağlılıkları yüksek hizmet alanların verilen hizmetten daha çok yarar sağlayacaklarını söylemek mümkündür (Kandampully ve Suhartanto, 2000; Atalık, 2006; Kandampully ve Hu, 2007, s.441). 
Bu araştırmada Anadolu Üniversitesi örgün öğrencilerinin üniversiteye olan bağllıkları, bağlılığ 1 etkilediği düşünülen üniversite imajı ve üniversite imajını etkilediği düşünülen fiziki imkânlar, akademik ve sosyokültürel faaliyetler bağlamında model yaklaşımıyla incelenmiştir. Geliştirilen bağlllık modelinin üniversiteye olan bağlılığı açıklayıp açıklamadığı test edilmiştir.

\section{Yöntem}

Araştırma öğrencilerin hâlihazırdavar olan görüşlerini olduğu haliyle ortaya çıkarmayı amaçlayan bir çalışma olduğundan betimsel bir araştırmadır. Veriler toplandıktan sonra nicel hale dönüştürülmüş ve ilişkiler nicel veriler üzerinden kurulmuştur. Bu haliyle araştırma betimsel nicel bir araştırmadır.

Evren ve Örneklem:

Araştırma evreni A.Ü. Yunusemre Kampüsü, İki Eylül Kampüsü ve Porsuk Meslek Yüksek Okulu’nda örgün öğrenim gören önlisans ve lisans öğrencilerinden oluşmaktadır. Bu evrenden fakülte ve bölüm bazında kota örneklemesine dayalı örnekleme yöntemiyle örneklem çekilmiştir. Örneklem 2226 kişiden oluşmuş̧ur.

\section{Veri toplama araçlari:}

Memnuniyet ölçeği: Öğrencilerin memnuniyet düzeylerini ölçmek amaciyla üç ana alt boyutta ölçme yapan, cevapların Likert tipi 5'li derecelendiği bir ölçme aracı geliştirilmiştir.

Ölçek danışmandan memnuniyet, öğretim elemanlarından memnuniyet, kültürel/sportif faaliyetlerden memnuniyet, idari işlemlerden memnuniyet, fiziksel imkanlardan memnuniyet ve güvenlikten memnuniyet olmak üzere sekiz boyutta ölçme yapmaktadır.

İmaj ve Bağlılığın Ölçülmesi: Öğrencilerin üniversiteye ilişkin imajlarını ölçmek amacıyla üç madde kullanılmıştır. Üniversiteye olan bağlılığı ölçmek için ise iki madde kullanılmıştır.

\section{Bulgular}

\section{Ölçüm Modeline iliş̧kin Analizler}

Ölçeğin genel kalitesini belirlemek amacıyla ölçeğin yakınsak (convergent) ve ayırtedici (discriminant) geçerlilik değerleri belirlenmiştir. Ayrıca maddele- rin faktör yükleri, parametre kestirimleri, çıkarılan ortalama varyans ve birleşik (composite) güvenirlik değerleri belirlenmiştir.

Bir ölçeğin genel kalitesini gösteren boyutlardan birisi maddelerinin faktör yüklerinin 0.50'nin üzerinde olması ve bu faktör yüklerinin anlamlı $\mathrm{t}$ değerlerine sahip olmasıdır (Bagozzi \& Yi, 1988; Hair, Black, Babin, \& Anderson, 2009). Bu çalı̧̧mada geliştirilen ölçeğin faktör yükleri 0.35 ile 0.97 arasındadır. Faktör yük değeri 0.50'nin altında bulunan 5 madde bulunmaktadır. Fiziki algıya yönelik ölçüm yapan dört madde (m41, m52, m54, m56) ile imaj algısını ölçen bir madde (m40) faktör yükleri 0.50 'nin altında bulunmasına rağmen (sırasıly $0.35 ; 0.38 ; 0.43 ; 0.43$; 0.44) Anadolu Üniversitesi'nin fiziksel altyapısına ilişkin önemli birimlere ve imajına ilişkin ölçme yaptığından ölçekten çıkarılmamıştır. Tüm maddelerin faktör yüklerinin $t$ değerleri 0.05 düzeyinde anlaml1lık için gerekli olan 1.96 değerinin üzerindedir. Faktör yükleri, $t$ değerleri ve anlamlılık düzeyleri Tablo 1'de gösterilmiştir. Değerler ölçeğin yakınsak (convergent) geçerliliği için yeterli kanıt sunmaktadır. Elde edilen faktör yüklerinin 0.50 'den büyük olması ve bu değerlere ilişkin $t$ değerlerinin anlamlılıklarının 0.05 'ten küçük olması ölçeğin yakınsak (convergent) geçerliliğinin yeterli düzeyde olduğunu göstermektedir. Bir ölçeğin ölçtüğünü iddia ettiği gizil değişkenin güvenilir olduğunu söyleyebilmek için birleşik (composite) güvenirliğinin 0.60 veya daha büyük olması gereklidir (Fornell ve Larcker, 1981).

Yukarıdaki kanıtlara ek olarak ölçeğin yakınsak ve ayırtedici geçerliliği için her gizil değişkenin ortalama çıkarılan varyans değerleri hesaplanmıştır. Bagozzi ve Yi (1988), ortalama çıkarılan varyans değerinin 0.50 ve üzerinde olmasını bir testin yakınsak ve ayırtedici geçerliliği için yeterli sınır olarak bildirmişlerdir. Tüm faktörlerin ortalama çıkarılan varyans değerleri sırasıyla şöyledir: akademik danışman buyutu (0.53), öğretim elemanı boyutu (0.40), kültürel/sportif faaliyetler boyutu (0.41), idari faaliyetler boyutu ( 0.37$)$, güvenlik boyutu (0.74), imaj boyutu (0.68), bağlllık boyutu (0.45) ve fiziki algı boyutu (0.18). Görüleceği gibi faktörlerden bazılarının ortalama çıkarılan varyans değeri 0.50 'nin altındadır. Fornell ve Larcker, (1981) ortalama çıkarılan varyans değerlerinin 
0.50'nin altında olduğu durumlarda birleşik güvenirlik değeri 0.60 'nn üzerindeyse ölçeğin yapı geçerliliğinin sağlanmış kabul edilebileceğini bildirmişlerdir. Tablol'de görüleceği üzere ölçeğin tüm boyutlarının birleşik güvenirlik değerleri 0.60 ’n üzerindedir. $\mathrm{Bu}$ doğrultuda, ölçeğin yeterli düzeyde yakınsak ve ayırtedici geçerliliği ve güvenilirliğiolduğu gösterilmiştir.

\section{Ölçeğin Yapısına İlişkin Analiz Sonuçları}

Ölçeğin yapısal modelinin uyum iyiliğini değerlendirmek için çok sayıda istatistik bulunmaktadır. Bu çalışmada Chi square/sd oranı (( $\left.c^{2} / d f\right)$, Normed Fit Index (NFI), non-Normed Fit Index (NNFI), Comperative Fit Index (CFI), Incremantal Fit Index (IFI) ve Root Mean Square Error of Approximation (RMSEA) istatistikleri model iyiliğini değerlendirmek için kullanılmıştır (Jöreskog ve Sorbom, 1996). Uyum indekslerinin kritik değerleri için aşağıdaki referans değerler dikkate alınmıştır (Hu ve Bentler, 1999).

Elde edilen uyum iyiliği istatistikleri sırasıyla şöyledir: Chi square $\left(c^{2}=5268.50, d f=1444, p<0.001\right)$, Chi square/df $\left(c^{2} / d f=3.65\right)$, RMSEA (0.034), NFI (0.97),
NNFI (0.98), CFI (0.98), IFI (0.98). Tüm uyum istatistikleri bir arada göz önünde bulundurulduğunda hepsinin birbirini destekler nitelikte yapısal modelin iyi derecede uyuma sahip olduğunu gösterdiği görülmektedir. Elde edilen uyum istatistiği sonuçlarına göre ölçek iyi derecede geçerli bulgular elde etmeye imkân tanımaktadır.

Alt ölçekler arası kovaryanslar ve alt ölçeklerin ortalama çıkarılan varyanslarının karekök değerleri aşağıda Tablo 2'de gösterilmiştir.

Yukarıda verileri güvenilir ve geçerli olarak topland1ğ 1 gösterilmiş olan ve araştırmada kullanılacak olan değişkenler arasındaki ilişkiler Yapısal Eşitlik Modellemesi (YEM) ile test edilmiştir. YEM'le test edilen kavramsal model aşağıda Şekil l'de verilmiştir.

Modele göre öğrencilerin Anadolu Üniversitesinin güvenlik ve fiziki olanaklardan oluşan fiziksel imkânlarına ilişkin algılıları; akademik, kültürel ve sportif olanaklardan oluşan faaliyetlere ilişkin alg1ları ve öğrencilere verilen akademik danışmanlık, öğretme çabası ve akademik gelişim imkânlarından

\begin{tabular}{ll}
\hline Uyum indeksi & Sınırlar \\
\hline Chi square/sd $\left(\chi^{2} / d f\right)$ & $<3$ iyi uyum \\
& $<5$ kabul edilebilir uyum \\
\hline $\mathrm{NFI}$ & $\geq 0.95$ iyi uyum \\
\hline $\mathrm{NNFI}$ & $\geq 0.95$ iyi uyum \\
\hline $\mathrm{CFI}$ & $\geq 0.95$ iyi uyum \\
\hline $\mathrm{IFI}$ & $\geq 0.95$ iyi uyum \\
\hline & $0.09-<0.10$ orta düzey uyum \\
RMSEA & 0.08 kabul edilebilir düzeyde uyum \\
& $\leq 0.05$ çok iyi uyum \\
\hline
\end{tabular}


Tablo 1. Faktör Yükleri, $t$-değerleri, OÇV ve BG değerleri

\begin{tabular}{|c|c|c|c|c|c|}
\hline Boyut & Madde No & Faktör Yükü & t-değeri* & $\mathrm{OÇV}^{* *}$ & $\mathrm{BG}^{* * *}$ \\
\hline \multirow{5}{*}{ Danışman } & M1 & 0.76 & 40.27 & \multirow{5}{*}{0.53} & \multirow{5}{*}{0.85} \\
\hline & M2 & 0.78 & 41.96 & & \\
\hline & M3 & 0.60 & 29.46 & & \\
\hline & M4 & 0.73 & 38.36 & & \\
\hline & M5 & 0.78 & 41.47 & & \\
\hline \multirow{12}{*}{ Öğretim Elemanı } & M6 & 0.58 & 28.94 & \multirow{12}{*}{0.40} & \multirow{12}{*}{0.87} \\
\hline & M7 & 0.65 & 33.08 & & \\
\hline & M8 & 0.70 & 36.04 & & \\
\hline & M9 & 0.64 & 32.63 & & \\
\hline & M10 & 0.52 & 25.02 & & \\
\hline & M11 & 0.59 & 29.25 & & \\
\hline & M12 & 0.59 & 29.23 & & \\
\hline & M13 & 0.63 & 31.60 & & \\
\hline & M14 & 0.63 & 31.57 & & \\
\hline & M15 & 0.52 & 25.19 & & \\
\hline & M16 & 0.56 & 27.39 & & \\
\hline & M17 & 0.73 & 38.36 & & \\
\hline \multirow{9}{*}{ Kültürel-Sportif Faaliyetler } & M18 & 0.54 & 25.88 & \multirow{9}{*}{0.41} & \multirow{9}{*}{0.93} \\
\hline & M19 & 0.57 & 27.59 & & \\
\hline & M20 & 0.66 & 33.32 & & \\
\hline & M21 & 0.56 & 26.89 & & \\
\hline & $\mathrm{M} 22$ & 0.62 & 30.81 & & \\
\hline & M23 & 0.66 & 33.32 & & \\
\hline & M24 & 0.65 & 32.82 & & \\
\hline & M25 & 0.72 & 37.56 & & \\
\hline & M26 & 0.72 & 37.49 & & \\
\hline \multirow{7}{*}{ İdari Faaliyetler } & M27 & 0.73 & 37.80 & \multirow{7}{*}{0.37} & \multirow{7}{*}{0.89} \\
\hline & M28 & 0.77 & 40.80 & & \\
\hline & M29 & 0.78 & 42.14 & & \\
\hline & M30 & 0.77 & 40.77 & & \\
\hline & M31 & 0.55 & 26.35 & & \\
\hline & M32 & 0.50 & 23.74 & & \\
\hline & M33 & 0.64 & 32.22 & & \\
\hline \multirow{2}{*}{ Güvenlik } & M34 & 0.86 & 36.43 & \multirow{2}{*}{0.74} & \multirow{2}{*}{0.92} \\
\hline & M35 & 0.88 & 37.25 & & \\
\hline \multirow{3}{*}{ İmaj } & M36 & 0.82 & 43.63 & $0<0$ & \\
\hline & M37 & 0.78 & 40.90 & 0,68 & 0,77 \\
\hline & M40 & -0.56 & -4.11 & & \\
\hline & M38 & 0.67 & 32.51 & & \\
\hline Bağlılık & M39 & 0.63 & 30.92 & 0,45 & 0,90 \\
\hline & M40 & 0.97 & 7.15 & & \\
\hline & M41 & 0.35 & 16.36 & & \\
\hline & M42 & 0.60 & 29.67 & & \\
\hline & M43 & 0.67 & 34.07 & & \\
\hline & M44 & 0.65 & 32.73 & & \\
\hline & M45 & 0.70 & 36.14 & & \\
\hline & M46 & 0.68 & 35.05 & & \\
\hline & M47 & 0.61 & 30.53 & & \\
\hline & M48 & 0.64 & 32.33 & & \\
\hline Fiziki & M49 & 0.55 & 26.60 & 0,18 & 0,96 \\
\hline & M50 & 0.60 & 29.89 & & \\
\hline & M51 & 0.52 & 25.26 & & \\
\hline & M52 & 0.38 & 17.67 & & \\
\hline & M53 & 0.52 & 25.31 & & \\
\hline & M54 & 0.43 & 20.44 & & \\
\hline & M55 & 0.50 & 23.40 & & \\
\hline & M56 & 0.43 & 20.50 & & \\
\hline üm t değerleri 0,01 düze & e anlamlidır & & & & \\
\hline OCCV (AVE): Ortalama C & lan Varyan & $\overline{/\left[\Sigma \lambda^{2}+\Sigma(\theta)\right]}$ & & & \\
\hline
\end{tabular}


Tablo 2. Kovaryans Matrisi

\begin{tabular}{|c|c|c|c|c|c|c|c|c|}
\hline & Danışman & $\begin{array}{l}\text { Ögretim } \\
\text { Elemanı }\end{array}$ & \multicolumn{2}{|c|}{ Kültürel/Sportif İdari } & Güvenlik & İmaj & Bağlılık & Fizik \\
\hline$\overline{\text { Danışman }}$ & $0.73 *$ & & & & & & & \\
\hline Öğretim Elemanı & 0.41 & $0.63 *$ & & & & & & \\
\hline Kültürel/Sportif & 0.26 & 0.43 & $0.64 *$ & & & & & \\
\hline İdari & 0.25 & 0.52 & 0.47 & $0.61^{*}$ & & & & \\
\hline Güvenlik & 0.13 & 0.26 & 0.24 & 0.37 & $0.86^{*}$ & & & \\
\hline Bağlılık & 0.23 & 0.45 & 0.27 & 0.35 & 0.27 & $0.82 *$ & & \\
\hline İmaj & 0.27 & 0.57 & 0.34 & 0.43 & 0.29 & 1.03 & $0.67 *$ & \\
\hline Fizik & 0.22 & 0.41 & 0.38 & 0.38 & 0.31 & 0.48 & 0.61 & $0.42 *$ \\
\hline
\end{tabular}

"Köşegende bulunan değerler ortalama çıkarılan varyans değerlerinin kareköküdür.

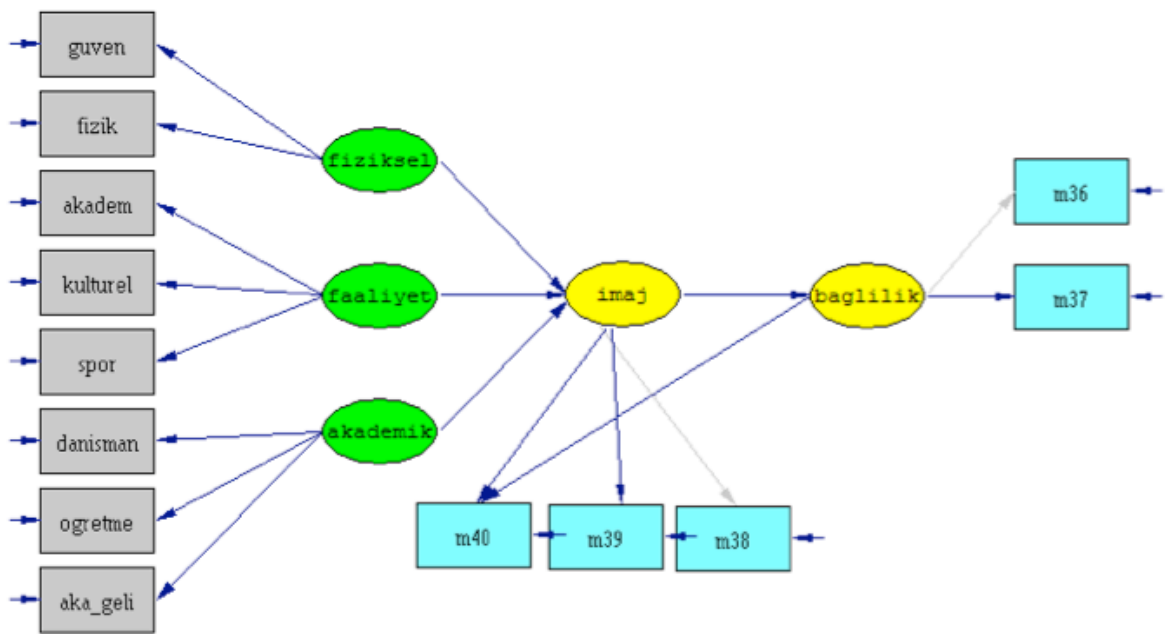

Şekil 1. Öğrenci Bağılığı Kavramsal Modeli

oluşan akademik alanda yürütülen faaliyetlere ilişkin algıları üniversitenin öğrencilerin gözündeki imajını etkilemektedir. Sayılan faktörlerden etkilenen imaj ise öğrencilerin üniversiteye olan bağlllıklarını etkilemektedir. Toplanan verilerin bu modelle iddia edilen etkileri gösterip göstermediğini test etmek amacıyla gizil değişkenlerden oluşan yapısal eşitlik modellemesi analizi kullanılmıştır. Aşağıda önce veriler ile model arasındaki uyumu gösteren uyum iyiliği (goodness of fit) değerleri verilmiş ardından modeldeki etki yollarının değerleri verilmiştir.Modelin analizi sonucunda modelin genelinin yol katsayıları aşağıda Şekil 2'de verilmiştir.
Modelin uyum iyiliğini incelemek amacıyla elde edilen katsayılar sırasıyla şöyledir: Chi square $\left(c^{2}=\right.$ 137.82, $d f=52, p<0.001)$, Chi square/df $\left(c^{2} / d f=2.65\right)$, RMSEA (0.027), NFI (0.99), NNFI (0.99), CFI (1.00), IFI (1.00). Modeli iyiliği katsayıları için Elde edilen değerler modelin toplanan verilerle çok iyi uyum sağladığını göstermektedir.

YEM analizleri şu sonuçları vermiștir: (1) Anadolu Üniversitesinin fiziksel imkânları ve güvenlik önlemlerinden oluşan Fiziksel yeterlilik algısı, üniversite imajinı etkilemektedir $\left(\gamma_{11}=0.56, \mathrm{t}=9.64, \mathrm{p}<0.001\right)$; (2) Akademik gelişme imkanlarına, kültürel faaliyetlere ve sportif faaliyetlere ilişkin algılardan oluşan Faaliyet algısı, üniversite imajını etkilemektedir $\left(\gamma_{11}=-\right.$ 


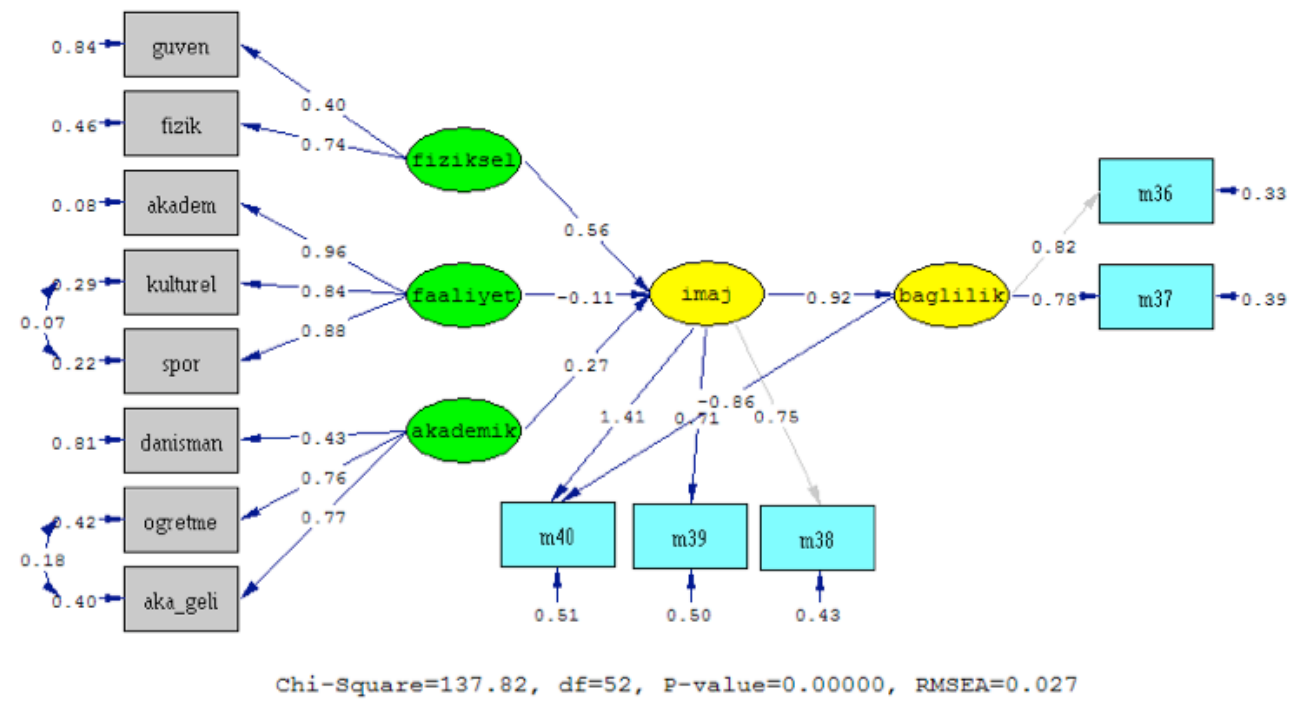

Şekil 2. Modele İlişkin Yol Katsayıları

0.11, $\mathrm{t}=-3.81, \mathrm{p}<0.01$ ); danışman öğretim elemanına, öğretim elemanına ve kişisel akademik gelişim imkanlarına yönelik algılardan oluşan akademik gelişim algısı üniversite imajını etkilemektedir $\left(\gamma_{11}=0.27, \mathrm{t}=-\right.$
5.29, $\mathrm{p}<0.01$ ), fiziksel yeterlilik, faaliyet ve akademik gelişim algılarından etkilenen üniversite imajı üniversiteye olan bağll1 $\breve{g}_{1}$ etkilemektedir $\left(\gamma_{11}=0.92, \mathrm{t}=-\right.$ 26.18, $\mathrm{p}<0.01)$

Tablo 3. YEM Yol Katsayıları ve t Değerleri

\begin{tabular}{lllll}
\hline Hipotez & İlişki yolu & Yol katsayısı & t değeri & Sonuç \\
\hline $\mathrm{H}_{1}$ & FIZIKSEL $\rightarrow$ IMAJ & 0.56 & 9.64 & Doğrulandı \\
$\mathrm{H}_{2}$ & FAALIYET $\rightarrow$ IMAJ & -0.11 & -3.81 & Doğrulandı \\
$\mathrm{H}_{3}$ & AKADEMIK $\rightarrow$ IMAJ & 0.27 & 5.29 & Doğrulandı \\
$\mathrm{H}_{4}$ & IMAJ $\rightarrow$ BAGLILIK & 0.92 & 26.18 & Doğrulandı \\
\hline
\end{tabular}

\section{Tartışma}

Araştırma sonucunda elde edilen bulgular Anadolu Üniversitesi örgün öğrencilerinin memnuniyet durumlarını, üniversiteye yönelik imajlarını ve bağlılıklarını ölçen ölçme araçlarının yüksek derecede geçerli ve güvenilir olduğunu göstermiştir. Ölçek Anadolu Üniversitesi’nde ya da başka üniversitelerde örgün öğrencilerin memnuniyetini ölçmek amacıyla kullanılabilecek bir ölçme aracıdır.

Anadolu Üniversitesi örgün öğrencilerinin üniversiteye olan bağlılıklarını etkileyen faktörleri içeren bağlılık modelinin iyi derecede uyumla çalıştı̆̆ 1 gö- rülmüştür. Buna göre öğrencilerin fiziksel koşullardan, akademik imkânlardan ve sosyo-kültürel faaliyetlerden duydukları memnuniyet üniversite imajını etkilemektedir. Bu üniversite imajı ise örgün öğrencilerinin üniversiteye olan bağll1ıklarını etkilemektedir. Örgün eğitim gören öğrencilerin üniversite imajını en çok etkileyen faktör fiziksel koşullardan duydukları memnuniyettir. Öğrencilerin üniversite imajlarını en az etkileyen faktör ise sosyokültürel faaliyetlerden duydukları memnuniyettir. Öğrencilerin memnuniyetlerinden etkilenen üniversite imajı ise öğrencilerin üniversiteye olan bağlılıkları yüksek derecede etkilemektedir $(0,92)$. 
Yukarıdaki bulgular bütün olarak göz önünde bulundurulduğunda Anadolu Üniversitesi örgün öğrencileri fiziksel olarak iyi düzenlenmiș güvenli bir ortamda bulundukları için üniversiteye yönelik olumlu bir imaj geliştirmekte ve fiziksel ortamdan kaynaklanan olumlu imaja bağlı olarak üniversiteye kendilerini bağlı hissetmektedirler. Öğrencilerim üniversiteye yönelik olumlu imajlarını etkilemede akademik ve sosyokültürel faaliyetlerin etkisi olmakla birlikte çok yüksek değildir.

\section{Kaynakça}

Atalık Ö. (2006). Havayolu İşletmeleri Örneğinde İşletme İmajının Havayolu İşletmesi Tercihlerine ve Müşteri Bağlılığına Olan Etkisinin Belirlenmesine Yönelik Bir Araştırma, (Çevrimiçi) http:// www.akademikbakis.Org/pdfs/7/Anadolu.pdf, 04.02.2010

Bagozzi, R. P. \& Yi, Y. (1988). On the evaluation of structural equation models. Journal of the Academy of Marketing Science, 16, 74-94.

Barak, M., Watted, A., \& Haick, H. (2016). Motivation to learn in massive open online courses: Examining aspects of language and social engagement. Computers \& Education, 94, 49-60.

Brooks, R., Brooks, S., \& Goldstein, S. (2012). The power of mindsets: Nurturing engagement, motivation, and resilience in students. In Handbook of research on student engagement (pp. 541-562). Springer US.

Clark, R. K., Walker, M., \& Keith, S. (2002). Experimentally Assessing the Student Impacts of Out-ofClass Communication: Office Visits and the Student Experience. Journal of College Student Development, 43(6), 824-37.

Delialioğlu, Ö. (2012). Student engagement in blended learning environments with lecture-based and problem-based instructional approaches. Journal of Educational Technology \& Society, 15(3), 310322.
Dixson, M. D. (2012). Creating effective student engagement in online courses: What do students find engaging?. Journal of the Scholarship of Teaching and Learning, 10(2), 1-13.

Dolmans, D. H., Wolfhagen, H. A., \& Scherpbier, A. J. (2003). From quality assurance to total quality management: how can quality assurance result in continuous improvement in health professions education?. Education for Health (Abingdon, England), 16(2), 210-217.

Draus, P. J., Curran, M. J., \& Trempus, M. S. (2014). The influence of instructor-generated video content on student satisfaction with and engagement in asynchronous online classes. Journal of Online Learning and Teaching,10(2), 240-254.

Fornell, C., \& Larcker, D. F. (1981). Evaluating structural equation models with unobservable variables and measurement error. Journal of marketing research, 39-50.

Gibbs, R., \& Poskitt, J. (2010). Student Engagement in the Middle Years of Schooling (Years 7-10): Literature Review, Ministry of Education, New Zealand.

Guolla, M. (1999). Assessing the teaching quality to student satisfaction relationship: Applied customer satisfaction research in the classroom. Journal of marketing theory and practice, 87-97.

Hair, F. J., Black, W. C., Babin, B. J., \& Anderson, R. E. (2009). Multivariate Data Analysis: A global perspective. 7th ed. New York: Macmillan.

Healey, M., Flint, A., Harrington, K. 2014. Engagement through partnership: students as partners in learning and teaching in higher education, https:// www.heacademy.ac.uk/sites/default/files/resources/engagement_through_partnership.pdf

Henrie, C. R., Bodily, R., Manwaring, K. C., \& Graham, C. R. (2015). Exploring intensive longitudinal measures of student engagement in blended learning. The International Review of Research in Open and Distributed Learning, 16(3). 
Hu, L. T., \& Bentler, P. M. (1999). Cutoff criteria for fit indexes in covariance structure analysis: Conventional criteria versus new alternatives. Structural equation modeling: a multidisciplinary journal, 6(1), 1-55.

Johnston, H. 2008. Extracurricular Activities and Student Achievement: Everyone Gains, http://oregongearup.org/files/research-briefs/extracurricularactivities.pdf

Jones, R. D. (2008). Strengthening student engagement. International Center for Leadership in Education, 1 .

Joo, K. P., Andrés, C., \& Shearer, R. (2014). Promoting distance learners' cognitive engagement and learning outcomes: Design-based research in the Costa Rican National University of Distance Education. The International Review of Research in Open and Distributed Learning, 15(6).

Joo, Y. J., Lim, K. Y., \& Kim, E. K. (2011). Online university students' satisfaction and persistence: Examining perceived level of presence, usefulness and ease of use as predictors in a structural model. Computers \& education,57(2), 1654-1664.

Kahu, E. R., Stephens, C., Leach, L., \& Zepke, N. (2013). The engagement of mature distance students. Higher Education Research \& Development, 32(5), 791804.

Kandampully J. ve H.Hu (2007), "Do Hoteliers Need to Manage Image to Retain Loyal Customers", International Journal of Contemporary Hospitality Management, Vol 19, No:6, pp 435-443.

Kandampully J. ve D. Suhartanto (2000), "Customer Loyalty in the Hotel Industry: The Role of Customer Satisfaction and Image", International Journal of Contemporary Hospitality Management, Vol 12, No: 6, pp 346-351.
Karakütük, K., Tunç, B., Bülbül, T., Özdem, G., Taşdan, M., Çelikkaleli, Ö., \& Bayram, A. (2012). The adequacy of physical conditions of public high schools in Turkey according to their sizes. Ankara University, Journal of Faculty of Educational Sciences, 45(2), 183-204.

King, M. C. (1993). Academic Advising: Organizing and Delivering Services for Student Success. New Directions for Community Colleges, Number 82. New Directions for Community Colleges.

King, M. C. (1993). Academic Advising: Organizing and Delivering Services for Student Success. New Directions for Community Colleges, Number 82. New Directions for Community Colleges.

Kuh, G. D., \& Hu, S. (2001). The effects of student-faculty interaction in the 1990s. The Review of Higher Education, 24(3), 309-332.

Kuo, Y. C., Walker, A. E., Belland, B. R., \& Schroder, K. E. (2013). A predictive study of student satisfaction in online education programs. The International Review of Research in Open and Distributed Learning, 14(1), 16-39.

Kuo, Y. C., Walker, A. E., Schroder, K. E., \& Belland, B. R. (2014). Interaction, Internet self-efficacy, and self-regulated learning as predictors of student satisfaction in online education courses. The Internet and Higher Education, 20, 35-50.

Liaw, S. S. (2008). Investigating students' perceived satisfaction, behavioral intention, and effectiveness of e-learning: A case study of the Blackboard system. Computers \& Education, 51(2), 864-873.

Maslow, A. H. (1943). A theory of human motivation. Psychological review,50(4), 370.

Massachusetts Task Force Report,(2014). School Safety and Security, Massachusetts Task Force Report of School Safety and Security 
NCPC, (2003). School Safety and Security Toolkit, 2003 National Crime Prevention Council Washington

NEALS,(2009). Improving School Sport and Physical Education in your School, Student Learning Division Office of Government School Education Department of Education and Early Childhood Development Melbourne, State of Victoria

Phan, T., McNeil, S. G., \& Robin, B. R. (2016). Students' patterns of engagement and course performance in a Massive Open Online Course.Computers \& Education, 95, 36-44.

Popli, S. (2005). Ensuring customer delight: A quality approach to excellence in management education. Quality in Higher Education, 11(1), 17-24.
Shen, D., Cho, M. H., Tsai, C. L., \& Marra, R. (2013). Unpacking online learning experiences: Online learning self-efficacy and learning satisfaction. The Internet and Higher Education, 19, 10-17.

Towler, V. 2010. Student engagement literature review, Department of Educational Research Lancaster University, https://www.heacademy.ac.uk/sites/default/files/studentengagementliteraturereview_1. pdf

Wilms, J. D. (2000). Student engagement at school: A sense of belonging and participation. Results from PISA. Paper of OECD. 